\title{
Narrow carbonyl resonances in proton-diluted proteins facilitate NMR assignments in the solid-state
}

\author{
Rasmus Linser • Uwe Fink • Bernd Reif
}

Received: 16 December 2009/Accepted: 1 March 2010/Published online: 16 March 2010

(C) Springer Science+Business Media B.V. 2010

\begin{abstract}
HNCO} / \mathrm{HNCACO}$ type correlation experiments are an alternative for assignment of backbone resonances in extensively deuterated proteins in the solid-state, given the fact that line widths on the order of 14-17 Hz are achieved in the carbonyl dimension without the need of high power decoupling. The achieved resolution demonstrates that MAS solid-state NMR on extensively deuterated proteins is able to compete with solution-state NMR spectroscopy if proteins are investigated with correlation times $\tau_{\mathrm{c}}$ that exceed $25 \mathrm{~ns}$.
\end{abstract}

Keywords Perdeuteration ·

MAS solid-state NMR spectroscopy · Micro-crystalline . PRE · Proton detection

\section{Introduction}

Nuclear Magnetic Resonance has become one of the major techniques for investigation of protein structure and function. In contrast to X-ray crystallography, NMR can also be used to investigate protein dynamics and does not rely on the availability of single crystals. For non-soluble species like membrane proteins (Lange et al. 2006) or fibrillar structures (Wasmer et al. 2008), MAS (Magic Angle Spinning) solidstate NMR is more and more becoming a powerful complementary technique to solution-state NMR. In the solid state, the line width depends on factors like sample

R. Linser · U. Fink · B. Reif $(\bowtie)$

Leibniz-Institut für Molekulare Pharmakologie (FMP),

Robert-Rössle Str. 10, 13125 Berlin, Germany

e-mail: reif@fmp-berlin.de

B. Reif

Charité Universitätsmedizin, 10115 Berlin, Germany homogeneity, MAS frequency and the efficiency of homoand heteronuclear decoupling. The tumbling correlation time and thus the molecular weight of the protein is of no importance, as internal dynamics, which are responsible for relaxation, are independent of the size of the molecule. This allows to achieve narrow lines for large proteins in the crystalline state (Tian et al. 2009) as well as in tumbling impaired solutions (Mainz et al. 2009). Using highly deuterated proteins, we obtain line widths for ${ }^{1} \mathrm{H}$ and ${ }^{15} \mathrm{~N}$ which are on the order of 20 and $10 \mathrm{~Hz}$, respectively (Chevelkov et al. 2006). In comparison to standard solid-state NMR experiments carried out on protonated samples, the achieved heteronuclear line width in case of a perdeuterated protein is not dependent on the efficiency of high power decoupling. Triple resonance experiments involving a proton dimension for detection thus become more and more routine in solidstate NMR (Linser et al. 2008, 2009; Schanda et al. 2009; Zhou et al. 2007). Conventional assignment strategies in the solid-state rely on resolved ${ }^{15} \mathrm{~N}$ chemical shifts (Baldus 2002; Pauli et al. 2001). Introducing a second chemical shift dimension facilitates resolving chemical shift degeneracies. Extensive deuteration is achieved by crystallizing the perdeuterated protein in a buffer which contains $\mathrm{H}_{2} \mathrm{O}$ and $\mathrm{D}_{2} \mathrm{O}$ in a ratio of around 10-30\% (Akbey et al. 2009; Chevelkov et al. 2006).

\section{Materials and methods}

We used a perdeuterated sample of the SH3 domain of chicken $\alpha$-spectrin, which was obtained by recombinant protein expression and purified as described previously (Chevelkov et al. 2007). Crystallization was induced in a buffer by a $\mathrm{pH}$-shift from 3.5 to 7.5. To achieve a high degree of deuteration, the crystallization buffer contained $\mathrm{H}_{2} \mathrm{O}$ and 


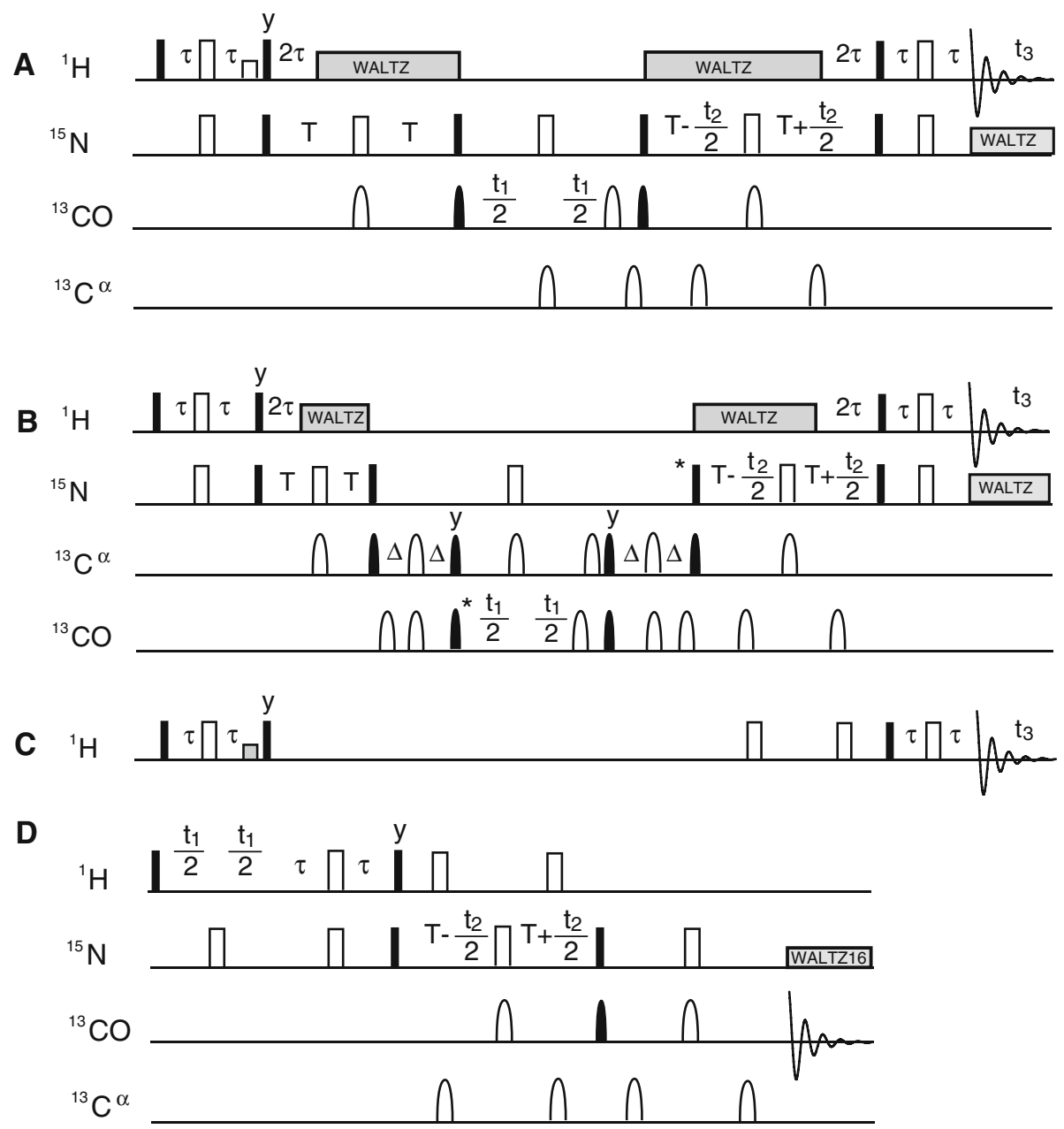

Fig. 1 a Pulse sequence for the ${ }^{1} \mathrm{H}$ detected $\mathrm{HNCO}$ experiment. Open bars refer to $180^{\circ}$ pulses, closed ones to $90^{\circ}$ pulses. Rectangular and curved bars refer to hard and shaped pulses, respectively. b Pulse sequence for the ${ }^{1} \mathrm{H}$ detected $\mathrm{HNCACO}$ experiment. The ${ }^{13} \mathrm{C}$ carrier frequency was switched from $\mathrm{C}^{\alpha}$ to $\mathrm{CO}$ directly before and after the $t_{1}$ evolution period. Selective on-resonance pulses on the ${ }^{13} \mathrm{C}$ channel were executed as soft rectangular pulses. Off-resonance selective pulses were implemented using G3 Gaussian cascade shapes (Emsley and Bodenhausen 1989; Emsley and Bodenhausen 1990). Pulses

$\mathrm{D}_{2} \mathrm{O}$ in a ratio of $1: 9$. We employed Paramagnetic Relaxation Enhancement (PRE) with $150 \mathrm{mM} \mathrm{Cu}$ (edta) for acceleration of data acquisition (Linser et al. 2007). After precipitation overnight, crystals were spun into a $3.2 \mathrm{~mm}$ rotor using approximately $15 \mathrm{mg}$ protein. All NMR experiments were carried out on a Bruker Biospin AVANCE spectrometer operating at a ${ }^{1} \mathrm{H}$ Larmor frequency of $600 \mathrm{MHz}$, using a $3.2 \mathrm{~mm}$ triple-resonance probe. The MAS frequency was adjusted to $24 \mathrm{kHz}$. The acquisition time in the ${ }^{15} \mathrm{~N}$ dimension in the triple resonance experiments was $t_{2}^{\max }=22 \mathrm{~ms}$. The effective temperature in the HNCO and HNCOCA was set to $\sim 22^{\circ} \mathrm{C}$. For the HNCACO correlation in Fig. 2, a temperature of $4^{\circ} \mathrm{C}$ was used. Data processing was performed using Bruker Topspin and Sparky (Goddard labeled with an asterisk were incremented according to TPPI. $\tau$, T, and $\Delta$ were set to $2.5,12$, and $4 \mathrm{~ms}$, respectively. c Alternative ${ }^{1} \mathrm{H}$ pulses for pulse schemes that use $180^{\circ}$ pulses instead of Waltz- 16 for scalar decoupling. The phase of the $2 \mathrm{nd}$ and $3 \mathrm{rd} 90^{\circ}{ }^{15} \mathrm{~N}$ pulse are changed by $90^{\circ}$. Otherwise, the pulse scheme is executed as indicated in (a and $\mathbf{b})$. The open bar with reduced height refers to a $1 \mathrm{~ms}$ purge pulse for water suppression. d Pulse sequence for the $J$-based ${ }^{13} \mathrm{C}$ detected HNCO experiment used to obtain the ${ }^{13} \mathrm{C}-1 \mathrm{D}$ spectrum represented for comparison in Fig. 3b

and Kneller). Apodization in the direct and indirect dimension was achieved by application of exponential multiplication using $10 \mathrm{~Hz}$ line broadening and gaussian multiplication using a line broadening of $-10 \mathrm{~Hz}$ and a shift of the bell by 0.1 , respectively.

\section{Results and discussion}

Complementary to the standard HNCA/HNCACB suite of experiments for assignment (Linser et al. 2008), we suggest to employ $\mathrm{HNCO}$ and HNCACO type experiments (Clubb et al. 1992; Engelke and Rüterjans 1995) to make use of the well-resolved $\mathrm{H}^{\mathrm{N}}, \mathrm{N}$, and $\mathrm{CO}_{\mathrm{i}-1} / \mathrm{CO}_{\mathrm{i}}$ resonances and the 
excellent resolution in the carbonyl dimension. Figure 1 shows the pulse sequences that we employ to record HNCO (A) and HNCACO (B). The scheme represented in (C) uses $180^{\circ}$ pulses to achieve proton scalar decoupling during the back-transfer from nitrogens to protons instead of the composite pulse sequence Waltz-16 (Shaka et al. 1983).

In combination with HNCACB type experiments, the use of carbonyl chemical shifts increases the reliability of the backbone assignments in the solid-state. A representative strip plot aligning inter- and intraresidual correlations for residues $9-18$ in the $\alpha$-spectrin SH3 domain is depicted in Fig. 2.

A 3D HNCO can be recorded in a few hours. An HNCACO with good signal to noise $\left(\sim 25: 1\right.$ for $\mathrm{CO}_{\mathrm{i}}$, recycle delay $530 \mathrm{~ms}$ ) can be recorded within 3 days. Correlations to $\mathrm{CO}_{\mathrm{i}-1}$ appear with a peak intensity of about $2 / 3$ in comparison to the $\mathrm{CO}_{i}$ peak intensity. In the $\mathrm{HNCACO}$, all of the assigned residues yield two correlations, except for L8, E22, N35, V46, R49 and S36, Q50, D62, for which we only find one and no correlation peak, respectively. Similarly, HNCOCA correlations can be recorded with the same pulse scheme, in which pulses on the $\mathrm{C}^{\alpha}$ channel are exchanged with pulses on the $\mathrm{CO}$ channel (Fig. 3).

$\mathrm{CO}$ resonances yield an improved dispersion in comparison to $\mathrm{C}^{\alpha}$ due the fact that homonuclear scalar decoupling is easily achieved in the carbonyl dimension. Figure $4 \mathrm{a}$ shows the first $2 \mathrm{D}{ }^{1} \mathrm{H},{ }^{13} \mathrm{CO}$ plane extracted from

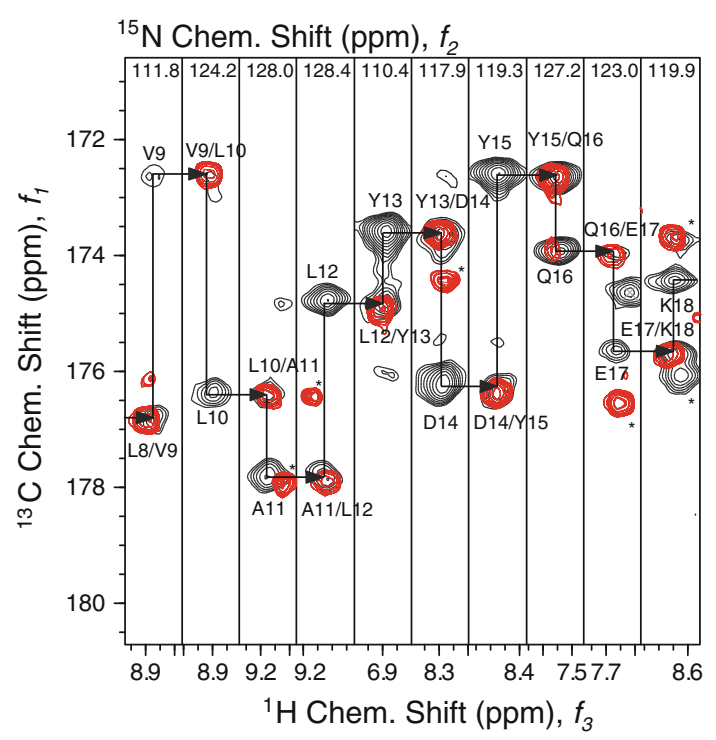

Fig. 2 Strip plots from a MAS solid-state NMR HNCACO experiment yielding sequential $\mathrm{H}^{\mathrm{N}}, \mathrm{N}^{\mathrm{H}}$, and $\mathrm{CO}_{\mathrm{i}-1}$ as well as intraresidual $\mathrm{H}^{\mathrm{N}}, \mathrm{N}^{\mathrm{H}}$, and $\mathrm{CO}_{\mathrm{i}}$ connectivities between residues L8 and $\mathrm{K} 18$ in the $\alpha$-spectrin SH3 domain (black contour lines). The spectra are superimposed with HNCO strip plots, which exclusively contain $\mathrm{H}^{\mathrm{N}}, \mathrm{N}^{\mathrm{H}}$, and $\mathrm{CO}_{\mathrm{i}-1}$ correlations (red contour lines). The 3D-HNCACO was recorded within 3 days using a $t_{1}^{\max }$ of $20 \mathrm{~ms}$

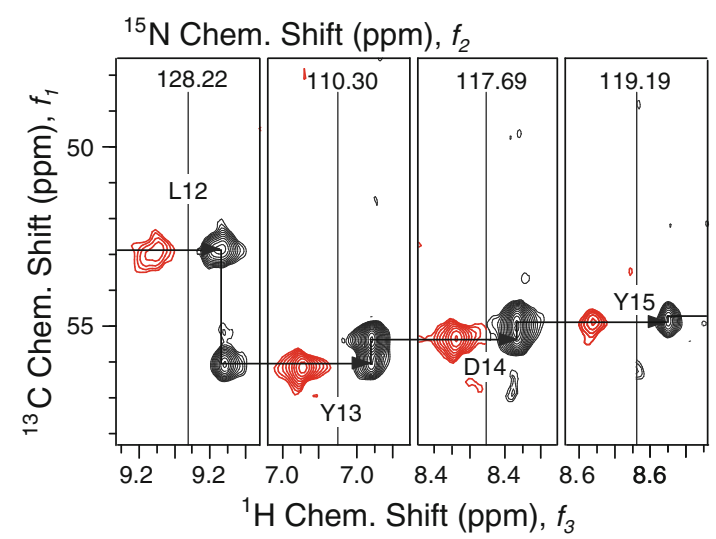

Fig. 3 Strip plots of the MAS solid-state NMR HNCOCA experiment showing residues L12-Y15 from the $\alpha$-spectrin SH3 domain. Sequential correlations can be obtained via the HNCA experiment (black). Unambiguous assignment is facilitated using the HNCOCA experiment (red), which exclusively yields interresidual $\mathrm{H}_{\mathrm{i}}^{\mathrm{N}}-\mathrm{N}_{\mathrm{i}}^{\mathrm{H}}-\mathrm{C}_{\mathrm{i}-1}^{\alpha}$ correlations. This experiment is complementary to the HNCA experiment, in which the intraresidual $\mathrm{H}_{\mathrm{i}}^{\mathrm{N}}-\mathrm{N}_{\mathrm{i}}^{\mathrm{H}}-\mathrm{C}_{\mathrm{i}}^{\alpha}$ correlation is more pronounced

a 3D HNCO experiment. Typically, we find line widths on the order of $14-17 \mathrm{~Hz}$ for the carbonyl resonance. Importantly, this resolution is achieved without heteronuclear decoupling and therefore represents an upper limit for the achievable resolution. In contrast, the effective $\mathrm{C}^{\alpha}$ line widths are typically on the order of $100 \mathrm{~Hz}$ due to evolution of ${ }^{13} \mathrm{C},{ }^{13} \mathrm{C}$ homonuclear and ${ }^{2} \mathrm{H},{ }^{13} \mathrm{C}^{\alpha}$ heteronuclear scalar couplings in the indirect dimension. The experimental $\mathrm{C}^{\alpha}$ and $\mathrm{CO}$ resonances for two representative residues are shown in Fig. $4 \mathrm{~b}$. The ${ }^{13} \mathrm{C}^{\prime}$ spectrum shown in the center of the Figure is extracted from a ${ }^{13} \mathrm{C}$ detected $\mathrm{HNCO}$ correlation which was recorded for comparison using the pulse scheme represented in Fig. 1d. In uniformly labeled proteins, a potentially favourable natural ${ }^{13} \mathrm{C}$ line width can only be exploited if all ${ }^{13} \mathrm{C},{ }^{13} \mathrm{C}$ scalar couplings are refocused effectively during the respective evolution period. Efficient homonuclear decoupling is readily achieved in indirect evolution periods involving carbonyl resonances. In contrast, ${ }^{13} \mathrm{C}$ detection in the direct dimension yields broad lines due to the evolution of homonuclear scalar couplings. Decoupling can here in principle be achieved using spin state selective experiments (Duma et al. 2003; Laage et al. 2009), by application of homonuclear decoupling in the direct dimension (Chevelkov et al. 2005) or by processing the data using $J$-deconvolution (Agarwal et al. 2009). These techniques, however, usually compromise the sensitivity of the experiment. Effective homonuclear decoupling in the $\mathrm{C}^{\alpha}$ indirect dimension in a HNCA correlation is difficult given the poor separation of the $\mathrm{C}^{\alpha}$ and $\mathrm{C}^{\beta}$ resonances. Use of a constant-time element (Chen et al. 2007; Yamazaki et al. 1994) in the pulse sequence overcomes this issue. However, sensitivity is significantly 

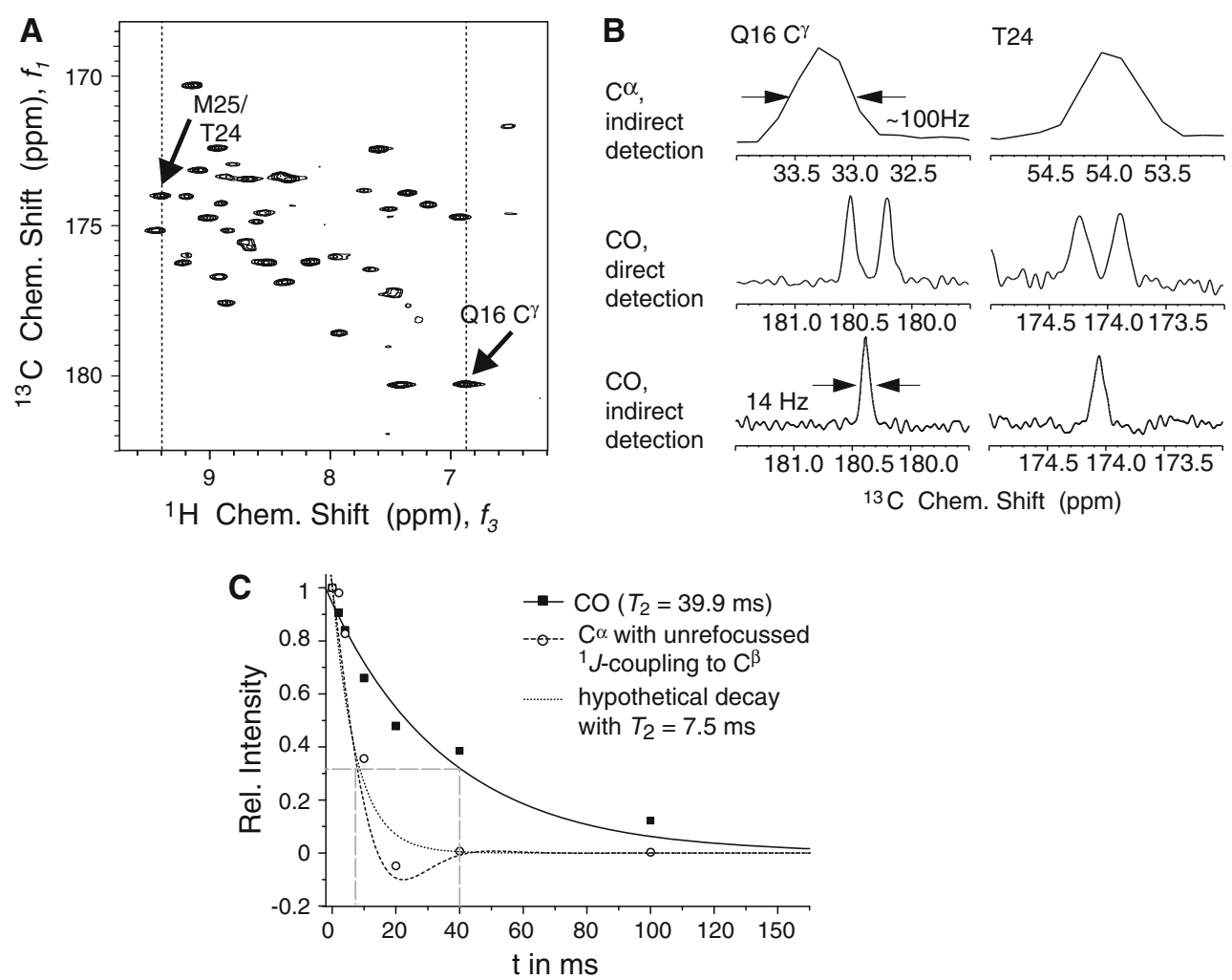

Fig. 4 a First $2 \mathrm{D}{ }^{13} \mathrm{CO},{ }^{1} \mathrm{H}^{\mathrm{N}}$ plane of the $3 \mathrm{D}$ MAS solid-state $\mathrm{HNCO}$ experiment, showing the favourable dispersion of the $\mathrm{CO}$ chemical shifts for the $\alpha$-spectrin SH3 domain. b 1D traces extracted from a typical solid-state HNCA (only $\mathrm{C}^{\alpha}$, $\mathrm{CO}$ decoupling, top) and $\mathrm{HNCO}$ experiment recorded without $\left({ }^{13} \mathrm{C}\right.$ detection, center) and with ${ }^{13} \mathrm{CO},{ }^{13} \mathrm{C}^{\alpha}$ decoupling $\left({ }^{1} \mathrm{H}\right.$ detection, bottom), respectively. The frequency axes of the $1 \mathrm{D}$ spectra are plotted to the same scale in the ${ }^{13} \mathrm{C}^{\alpha}$ and $\mathrm{CO}$ spectral region. The HNCA and HNCO were acquired using a $t_{1}^{\max }$ of 9 and $100 \mathrm{~ms}$, respectively. No apodization

compromised due to the length of the constant time period. In case standard triple-resonance probes are employed, $\mathrm{C}^{\alpha}$ resonances are slightly broadened due to evolution of scalar couplings to ${ }^{2} \mathrm{H}$. In the future, quadruple resonance probes that have an additional channel for ${ }^{2} \mathrm{H}$ will allow to overcome this problem.

In order to put the achievable resolution in the solidstate in context, we compared the experimental line width obtained here with the line width expected in solution. In solution, molecular tumbling can compromise sensitivity and resolution depending on the molecular weight of the dissolved protein. The transverse relaxation rates $R_{2}=1 / T_{2}$ crucially depend on the correlation time $\tau_{\mathrm{c}}$ of rotational diffusion, which increases for proteins with increasing molecular weight (Dayie and Wagner 1997; Lee et al. 2006). Even though there are examples of investigations on large protein complexes (Tugarinov et al. 2002; Tugarinov et al. 2009), solution-state NMR is inherently linked to small or intermediate sized molecules. In general, transverse relaxation of carbonyl carbons in a protein is was used in the $\mathrm{CO}$ dimensions. c Signal decay during an indirect carbon evolution period. The solid line (black squares) represents $\mathrm{CO}$ transverse magnetization (with ${ }^{13} \mathrm{C}^{\alpha},{ }^{13} \mathrm{CO}$ decoupling), while the dashed line (open circles) refers to $\mathrm{C}^{\alpha}$ (with ${ }^{13} \mathrm{C}^{\alpha},{ }^{13} \mathrm{CO}$ and ${ }^{2} \mathrm{H},{ }^{13} \mathrm{C}^{\alpha}$ decoupling). ${ }^{1} J_{\mathrm{C} \alpha \mathrm{C} \beta}$ can not be efficiently refocused due to overlap of $\mathrm{C}^{\alpha}$ and $\mathrm{C}^{\beta}$ chemical shifts. This results in a fast signal decay. The effective line width corresponds to an apparent $T_{2}^{\text {app }}$ of $\sim 7.5 \mathrm{~ms}$. In case ${ }^{2} \mathrm{H},{ }^{13} \mathrm{C}$ scalar couplings are not refocused, the apparent decay is even faster

dominated by chemical shift anisotropy (CSA). The respective relaxation rate $R_{2, \mathrm{CSA}}$ is given as (Dayie and Wagner 1997)

$R_{2, \mathrm{CSA}}=\left(d_{\mathrm{CSA}}^{2} \omega_{\mathrm{C}}^{2} / 6\right)\left[4 J_{\mathrm{C}^{\prime}}(0)+3 J_{\mathrm{C}^{\prime}}\left(\omega_{\mathrm{C}}\right)\right]$,

with a generalized CSA coupling constant $d_{\text {CSA }}^{2}=(1 / 3)$ $\Delta \delta^{2}\left[1+\eta^{2} / 3\right]=6.2 \times 10^{-9}$, (Engelke and Rüterjans 1997), where $\Delta \delta$ and $\eta$ represent the anisotropy and the asymmetry of the CSA tensor, respectively. $J_{\mathrm{C}^{\prime}}(\omega)$ refers to the spectral density function at frequency $\omega$.

A calculation of the expected ${ }^{13} \mathrm{CO}$ relaxation rates in solution at $14.1 \mathrm{~T}$ (corresponding to a ${ }^{1} \mathrm{H}$ Larmor frequency of $600 \mathrm{MHz}$ ) is shown in Fig. 5, together with the experimental solid-state decay rate (Fig. 4c). For illustration, solution-state correlation times for ubiquitin, the CDK inhibitor $\mathrm{p} 19^{\mathrm{INK} 4 \mathrm{~d}}$, malate synthase $\mathrm{G}$ and the "half proteasome", are drawn into the figure (Renner et al. 1998; Tjandra et al. 1995; Tugarinov et al. 2002, 2009). The simulation of the solution-state ${ }^{13} \mathrm{C}^{\prime}$ relaxation rates assume order parameters $\mathrm{S}^{2}$ of 0.8 and 1.0, respectively 


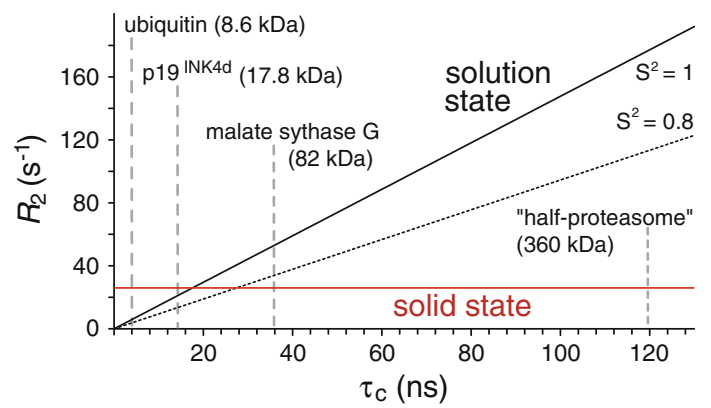

Fig. 5 Carbonyl transverse relaxation rates $R_{2}$ in solution and in the solid state. Whereas $R_{2}$ in solution (black) strongly depends on the correlation time $\tau_{\mathrm{c}}$, the line width in the solid-state is molecular weight independent. For the micro-crystalline $\mathrm{SH} 3$ domain, we find a value of $25 \mathrm{~s}^{-1}\left(T_{2}=40 \mathrm{~ms}, \mathrm{red}\right)$. The dashed black line shows ${ }^{13} \mathrm{CO}$ relaxation rates in solution assuming a generalized order parameter $S^{2}$ of 0.8 , while the solid black line is obtained assuming an order parameter of one. Vertical, dashed lines indicate typical values for the motional correlation time $\tau_{\mathrm{c}}$ for several proteins in solution. The calculation was carried out assuming an external magnetic field of $14.1 \mathrm{~T}(600 \mathrm{MHz})$

(Engelke and Rüterjans 1997). For intermediate or large proteins, the plot shows that the carbonyl resonance line width in the solid-state can potentially be smaller than the line width obtainable in solution. The break-even is reached for motional correlation times of $\tau_{\mathrm{C}} \sim 25 \mathrm{~ns}$.

The comparison given above assumes that the origin of line widths are sample homogeneity, residual homo- and heteronuclear dipolar couplings which are due to insufficient MAS rotation frequencies and decoupling, respectively, MA missetting and relaxation due to local dynamics. Other sources might involve the anisotropic magnetic susceptibility (Cowans and Grutzner 1993; Garroway 1977; Vanderhart et al. 1981). The estimated molecular weight at which solidstate NMR yields a more favourable resolution compared to solution-state NMR experiments therefore represents an upper limit that is implied by the current technology. We expect that with improved sample preparation and the availability of faster MAS rotation frequencies, the breakeven should rather be shifted towards lower molecular weights.

\section{Conclusion}

We have shown that solid-state NMR of extensively deuterated proteins yields excellent resolution in the ${ }^{1} \mathrm{H},{ }^{15} \mathrm{~N}$, and ${ }^{13} \mathrm{C}$ dimension. We find carbonyl line widths which are on the order of $14-17 \mathrm{~Hz}$. This makes the C' dimensionsimilar as in solution-state NMR - attractive for CO-based sequential backbone assignment using $\mathrm{HNCO} / \mathrm{HNCACO}$ experiments. Whereas in solution, relaxation increases with increasing molecular weight, the line width in the solid state is independent of tumbling and thus on the molecular weight. A break-even in resolution compared to solutionstate NMR is achieved for proteins with a molecular weight on the order of $\tau_{\mathrm{C}} \sim 25 \mathrm{~ns}$ (corresponding to proteins with $\sim 30 \mathrm{kDa}$ ). The fact that resolution does not depend on the molecular weight in the solid-state should pave the way for NMR investigations of large nanocrystalline proteins. We expect that high resolution spectra based on magnetization transfer schemes employing scalar couplings and proton detection will find widespread use, as high MAS speeds are becoming routinely available.

Acknowledgments We thank Peter Schmieder for continuous support. This research was supported by the Leibniz-Gemeinschaft (WGL) and the DFG (Re1435, SFB449, SFB740, FOR475). R. L. is a Kekulé scholar and acknowledges financial support by the Verband der Chemischen Industrie (VCI).

\section{References}

Agarwal V, Faelber K, Schmieder P, Reif B (2009) High-resolution double-quantum deuterium magic angle spinning solid-state NMR spectroscopy of perdeuterated proteins. J Am Chem Soc $131: 2-3$

Akbey Ü, Lange S, Franks WT, Linser R, Rehbein K, Diehl A, van Rossum B-J, Reif B, Oschkinat H (2009) Optimum levels of exchangeable protons in perdeuterated proteins for proton detection in MAS solid-state NMR spectroscopy. J Biomol NMR 46:67-73

Baldus M (2002) Correlation experiments for assignment and structure elucidation of immobilized polypeptides under magic angle spinning. Prog Nucl Magn Reson Spectrosc 41:1-47

Chen L, Kaiser JM, Polenova T, Yang J, Rienstra CM, Mueller LJ (2007) Backbone assignments in solid-state proteins using J-based 3D heteronuclear correlation spectroscopy. J Am Chem Soc 129:10650-10651

Chevelkov V, Chen Z, Bermel W, Reif B (2005) Resolution enhancement in MAS solid-state NMR by application of 13C homonuclear scalar decoupling during acquisition. J Magn Reson 172:56-62

Chevelkov V, Rehbein K, Diel A, Reif B (2006) Ultra-high resolution in proton solid-state NMR spectroscopy at high levels of deuteration. Angew Chem Int Ed 45:1-5

Chevelkov V, Faelber K, Schrey A, Rehbein K, Diehl A, Reif B (2007) Differential line broadening in MAS solid-state NMR due to dynamic interference. J Am Chem Soc 129:10195-10200

Clubb RT, Thanabal V, Wagner G (1992) A constant-time threedimensional triple-resonance pulse scheme to correlate intraresidue $1 \mathrm{HN}, 15 \mathrm{~N}$, and $13 \mathrm{CO}$ chemical shifts in $15 \mathrm{~N}-13 \mathrm{C}$-labeled proteins. J Magn Reson 97:213-217

Cowans BA, Grutzner JB (1993) Examination of homogeneous broadening in solids via rotationally synchronized spin-echo NMR-spectroscopy. J Magn Reson Ser A 105:10-18

Dayie KT, Wagner G (1997) Carbonyl carbon probe of local mobility in $13 \mathrm{C}, 15 \mathrm{~N}$-enriched proteins using high-resolution nuclear magnetic resonance. J Am Chem Soc 119:7797-7806

Duma L, Hediger S, Brutscher B, Böckmann A, Emsley L (2003) Resolution enhancement in multidimensional solid-state NMR spectroscopy of proteins using spin-state selection. J Am Chem Soc 125:11816-11817

Emsley L, Bodenhausen G (1989) Self-refocusing effect of $270^{\circ}$ gaussian pulses. Applications to selective two-dimensional exchange spectroscopy. J Magn Reson 82:211-221 
Emsley L, Bodenhausen G (1990) Gaussian pulse cascades: new analytical functions for rectangular selective inversion and inphase excitation in NMR. Chem Phys Lett 165:469-476

Engelke J, Rüterjans H (1995) Sequential protein backbone resonance assignments using an improved 3D-HN(CA)CO pulse scheme. J Magn Reson B 109:318-322

Engelke J, Rüterjans H (1997) Backbone dynamics of proteins derived from carbonyl carbon relaxation times at 500, 600 and $800 \mathrm{MHz}$ : application to ribonuclease T1. J Biomol NMR 9: 63-78

Garroway AN (1977) Homogeneous and inhomogeneous nuclear spin echoes in organic solids: adamantane. J Magn Reson 28:365-371

Goddard TD, Kneller DG SPARKY 3. University of California, San Francisco

Laage S, Lesage A, Emsley L, Bertini I, Felli IC, Pierattelli R, Pintacuda G (2009) Transverse-dephasing optimized homonuclear J-decoupling in solid-state NMR spectroscopy of uniformly 13C-labeled proteins. J Am Chem Soc 131:10816-10817

Lange A, Becker S, Seidel K, Giller K, Pongs O, Baldus M (2006) A concept for rapid protein-structure determination by solid-state NMR spectroscopy. Angew Chem Int Ed 44:2089-2092

Lee D, Hilty C, Wider G, Wüthrich K (2006) Effective rotational correlation times of proteins from NMR relaxation interference. J Magn Reson 176:72-76

Linser R, Chevelkov V, Diehl A, Reif B (2007) Sensitivity enhancement using paramagnetic relaxation in MAS solid-state NMR of perdeuterated proteins. J Magn Reson 189:209-216

Linser R, Fink U, Reif B (2008) Proton-detected scalar coupling based assignment strategies in MAS solid-state NMR spectroscopy applied to perdeuterated proteins. J Magn Reson 193:89-93

Linser R, Fink U, Reif B (2009) Probing surface accessibility of proteins using paramagnetic relaxation in solid-state NMR spectroscopy. J Am Chem Soc 131:13703-13708

Mainz A, Jehle S, van Rossum B-J, Oschkinat H, Reif B (2009) Large protein complexes with extreme rotational correlation times investigated in solution by magic-angle-spinning NMR spectroscopy. J Am Chem Soc 131:15968-15969

Pauli J, Baldus M, van Rossum B, de Groot H, Oschkinat H (2001) Backbone and side-chain $13 \mathrm{C}$ and $15 \mathrm{~N}$ signal assignments of the $\alpha$-spectrin SH3 domain by magic angle spinning solid-state NMR at 17.6 tesla. ChemBioChem 2:272-281
Renner C, Baumgartner R, Noegel AA, Holak TA (1998) Backbone dynamics of the CDK Inhibitor p19INK4d studied by ${ }^{15} \mathrm{~N}$ NMR relaxation experiments at two field strengths. J Mol Biol 283:221-229

Schanda P, Huber M, Verel R, Ernst M, Meier BH (2009) Direct detection of ${ }^{3 \mathrm{~h}} J_{\mathrm{NC}}$, hydrogen-bond scalar couplings in proteins by solid-state NMR spectroscopy. Angew Chem Int Ed 48:93229325

Shaka AJ, Keeler J, Frenkiel T, Freeman R (1983) An improved sequence for broadband decoupling: WALTZ-16. J Magn Reson $52: 335-338$

Tian Y, Chen L, Niks D, Kaiser JM, Lai J, Rienstra CM, Dunn MF, Mueller LJ (2009) J-Based 3D sidechain correlation in solidstate proteins. Phys Chem Chem Phys 11:7078-7086

Tjandra N, Feller SE, Pastor RW, Bax A (1995) Rotational diffusion anisotropy of human ubiquitin from 15N NMR relaxation. J Am Chem Soc 117:12562-12566

Tugarinov V, Muhandiram R, Ayed A, Kay LE (2002) Fourdimensional NMR spectroscopy of a 723-residue protein: chemical shift assignments and secondary structure of malate synthase G. J Am Chem Soc 124:10025-10035

Tugarinov V, Sprangers R, Kay LE (2009) Probing side-chain dynamics in the proteasome by relaxation violated coherence transfer NMR spectroscopy. J Am Chem Soc 129:1743-1750

Vanderhart DL, Earl WL, Garroway AN (1981) Resolution in C-13 NMR of organic-solids using high-power proton decoupling and magic-angle sample spinning. J Magn Reson 44:361-401

Wasmer C, Lange A, Melckebeke Hv, Siemer AB, Riek R, Meier BH (2008) Amyloid fibrils of the HET-s(218-289) prion form a beta solenoid with a triangular hydrophobic core. Science 319:15231526

Yamazaki T, Lee W, Revington M, Mattiello DL, Dahlquist FW, Arrowsmith CH, Kay LE (1994) An HNCA pulse scheme for the backbone assignment of $15 \mathrm{~N}, 13 \mathrm{C}, 2 \mathrm{H}$-labeled proteins: application to a 37-kDa Trp repressor-DNA complex. J Am Chem Soc 116:6464-6465

Zhou DH, Shea JJ, Nieuwkoop AJ, Franks WT, Wylie BJ, Mullen C, Sandoz D, Rienstra CM (2007) Solid-state protein structure determination with proton-detected triple resonance 3D magicangle spinning NMR spectroscopy. Angew Chem Int Ed 46: $8380-8383$ 